\title{
Prognostic Factors of the Postoperative Pancreatic Carcinoma and Implications for Identification of Potential Long-term Survivors
}

\section{Wei Hu}

Hubei University of Medicine

Jiao Zhou

Hubei University of Medicine

Wenbo Zhou

Hubei University of Medicine

Lun Wu ( $\square$ wulun0909@163.com )

Wuhan University Renmin Hospital

Shaohua Sun

Hubei University of Medicine

Zhen Zhang

Hubei University of Medicine

Hong-Sheng $\mathrm{Hu}$

Hubei University of Medicine

Feng Shen

Hubei University of Medicine

\section{Review}

Keywords: pancreatic cancer, prognosis factor, clinicopathologic feature, survival

Posted Date: December 12th, 2019

DOl: https://doi.org/10.21203/rs.2.18706/v1

License: (c) (i) This work is licensed under a Creative Commons Attribution 4.0 International License.

Read Full License 


\section{Abstract}

Background Patients with Pancreatic cancer (PC) have worse survival than patients with any other gastrointestinal malignancy. In present study, it is aim to investigate the prognostic factors of pancreatic carcinoma after curative resection .

Methods 72 cases suffered from pancreatic carcinoma or periampullary carcinoma received curative, nine clinicopathologic factors that could possibly influence survival for postoperative mortality and overall survival were selected for univariate analysis and multivariate analysis using Cox proportional hazard mode.

Results Univariate analysis showed that major factors of influence survival were size of the tumor, lymph node metastasis, and grade of differentiation $(\mathrm{P}<0.05)$. Multivariate analysis showed that lymph node metastasis and size of the tumor were the most important prognostic factors by multivariate analysis using the Cox proportional hazard model $(P<0.01)$.

Conclusions Prognostic factors of pancreatic carcinoma after resection are closed related to lymph node metastasis and the size of the tumor.

\section{Background}

Patients with Pancreatic cancer (PC) have worse survival than patients with any other gastrointestinal malignancy. It represents the fourth leading cause of cancer-related deaths in the United States, the fifth in European Union and the seventh in China ${ }^{[1,2]}$. Distant metastasis occurs in more than $50 \%$ of all the pancreatic carcinoma patients at presentation [3]. The exact causes of pancreatic cancer is little known, epidemiological studies have shown that smokers risk of pancreatic cancer 2-3 times higher than nonsmokers; alcohol, coffee, organic solvents are related to pancreatic cancer, diabetes may be an early clinical manifestation of pancreatic cancer, may also be risk factors for pancreatic cancer ${ }^{[4,5]}$. Numberous studies have also verified recurrent chronic pancreatitis is closely related to pancreatic cancer, but the degree of risk of pancreatitis secondary to pancreatic cancer remains controversial ${ }^{[6,7]}$.

At present, surgery for patient with pancreatic cancer is still the most effective treatment, and the operative mortality rate from the original $30 \%$ to the current $3 \%{ }^{[8]}$. However, post-surgical long-term survival is very poor. Although recent advances in surgical techniques, radiotherapy, and chemotherapy has to some extent improved the quality of life and time of patients with pancreatic cancer, the 5-year survival rate is only $3 \%$ to the current $5 \%-8 \%{ }^{[9]}$.

It has been reported that the poor prognosis is principally due to local tissue invasions, early tumor metastasis to regional lymph nodes, and the differentiation types of tumor cells ${ }^{[10]}$. An important prognostic factor for pancreatic carcinoma is the presence or absence of lymphatic and venous invasion. Studies have reported that patients with CA19-9 $>200 \mathrm{U} / \mathrm{ml}$ was diagnosed with pancreatic cancer and tumors rarely was completely resected when CA19-9 $>300 \mathrm{U} / \mathrm{ml}$. CA19-9 is an independent predictor of 
plasma in patients with recurrence and survival, which is closed correlation with treatment response ${ }^{[11,}$

12]. Various factors can influence the prognosis of the patients with pancreatic cancer after curative resection. In the present study, to explore the prognostic factors of postoperative after pancreatic cancer and attempt to better elucidate the determinants for receiving surgery and its impact on survival among patients with pancreatic cancer. We investigated the clinical and pathologic data of 72 patients undergoing pancreatic surgery at the Hubei University of Medicine, Dongfeng Hospital and analyzed the factors affecting the postoperative prognosis of pancreatic cancer clinical pathology using the Cox proportional hazard model. We specifically examined the impact of affecting the postoperative prognosis of pancreatic cancer and the outcomes of patients with pancreatic cancer who received surgery.

\section{Methods}

\section{Patients}

Pathology and clinical follow-up data were obtained from 72 patients [48 female, 34 male] undergoing pancreatic surgery for primary pancreatic adenocarcinoma in the department of hepatobiliary Surgery, Dongfeng Hospital between the years 2005 and 2013. The mean age of the patients was (58.7 \pm 8.4) years, with a range of 42-84. Pancreatic adenocarcinoma diagnosis was based on World Health Organization criteria. Tumor stages and clinicopathologic classification were defined based on the pathological tumor-node-metastasis (pTNM) classification ${ }^{13]}$. All specimens were examined histologically, and each tumor was classified as a well-differentiated $(n=26)$, moderately differentiated $(n=28)$, or poorly differentiated adenocarcinoma $(n=18)$, adenocarcinoma in 61 cases, 7 cases of squamous cell carcinoma, and acinar carcinoma in 4 cases according to the predominant histology. Clinicopathological factors including gender, age, tumor location, tumor size, pancreas surrounding tissue invasion, lymph node metastasis, clinical stage, pathological type, and pathological grade.

\section{Statistics}

Statistical analysis was performed using the $\mathrm{c} 2$ test. Survival curves were prepared using the KaplanMeier method, and statistical comparisons were made by the Cox proportional hazards model. A univariate comparison of the survival curves was made using the log-rank test. A Cox proportionalhazards analysis was used to determine the independent variables that influenced disease-free survival. Significance was considered as $p<0.05$. All statistical analyses were performed using SAS8.1 software.

\section{Result}

\section{Survival analysis and Univariate analysis of prognostic}

The overall survival follow-up ranged from 12 to 60 months with median of 12.6 months. Overall 1-, 2-, and 5-year survival estimates after operation were $38.9 \%(28 / 72), 11.11(8 / 72) \%$, and 0\%, respectively. Radical resection of the median survival time was 11 months. In univariable analysis, tumor size, lymph node metastasis, and pathological degree of differentiation were significant difference in survival ( $P$ 
$<0.05)$. The gender, age, tumor location, peripancreatic invasion, pathological type, and clinical stage were no significant difference $(P>0.05)$ between within one year and more than 1 year. The survival analysis results are shown in Table 1.

\section{Prognosis Cox multivariate analysis}

The prognostic effect of PC patients was investigated by comparing the survival rate of patients using Kaplan-Meier survival curves and the log-rank test. The mean survival time of PC patients with a high level of tumor size and lymph node metastasis were significantly shorter than that in the patients with other factors ( $42.5 \pm 6.4$ months; log-rank test, $\mathrm{P}<0.001$, Table 2 ). These results indicated that lymph node metastasis and tumor size were closely related to survival rate and prognosis of patients with pancreatic cancer (Figure1, 2).

\section{Discussion}

Cox regression survival analysis is often used in the medical prognosis of cancer and other diseases, the factors (covariates) analysis of the survival is a distinct role ${ }^{[14]}$. In this study, univariate analysis identified gender, age, tumor location, tumor size, tumor depth, lymph node metastasis, cancer stage, pathological type, and pathological grade as prognostic factors. Cox multivariate analysis showed that lymph node metastasis was one of the most important factors affecting the prognosis of pancreatic cancer. The survival rate of patients without lymph node metastasis was significantly higher than that with lymph node metastasis. The study have showed that pancreatic cancer is characterized by increased hyperplasia of fibrotic tissue and lymph node metastasis is an independent prognostic factor, metastasis to regional lymph nodes is one of the key indicators of aggressive tumors, lymph node status is a powerful predictor of patient survival ${ }^{[15]}$, which is consistent with the findings of the present study. The higher incidence of lymph node metastasis, 5year survival rate is also less than $7 \%$.

In current study, statistics of the cumulative frequency of lymph node metastasis were: paracancerous tissue $72.2 \%$ (52/72), paraduodenal $15.3 \%(11 / 72)$, superior mesentery artery $5.6 \%(4 / 72)$, posterior portal vein $4.2 \%(3 / 72)$, paracolon middle artery $2.8 \%(2 / 72)$. It showed that paracancerous tissues is lymph node metastasis and the highest frequency of the most concentrated areas. Studies have shown that lymphatic metastasis, tumor size, degree of differentiation, and pancreatic invasion like certain malignant tumors, lymph node metastasis has already existed when the tumor tumorigenesis ${ }^{[16,17]}$. In this study, it found that even diameters of early tumors were $<2 \mathrm{~cm}$, nearly $50 \%$ tumor had lymph node metastasis, which was consistent with previous studies.

Moreover, the size of the tumor is another important factor affecting the prognosis of pancreatic cancer surgery by cox model multivariate analysis. In general, the larger size of the tumor, the easier peripheral vascular pancreatic invasion and lymph node metastasis, which is low resection rate and poor prognosis $[18,19]$. In present study, it found that postoperative cumulative survival rate in patient of pancreatic cancer 
with tumor diameter $\leq 4 \mathrm{~cm}$ was significantly higher than patient with the diameter $>4 \mathrm{~cm}(P<0.05)$ (Fig. 2).

Therefore, lymph node metastasis and tumor size are the most important prognostic factors for pancreatic cancer surgery. It should pay more attention to select lymph node dissection in pancreatic surgery. However, long-term survival is not unsatisfied, even complete resection of the primary tumor and involved lymph node dissection. Numerous studies have shown that lymph node metastasis is closed to nerve-related violations, and is also found in the superior mesenteric artery (SMA) next to the peripheral nerve tissue distribution of the lymphatic capillaries, and pancreatic neural invasion is closely related to the lymphatic capillaries ${ }^{[20,21]}$. Although, the extended radical resection is effective way to improve the prognosis, the recurrence rate of pancreatic cancer is not decreased significantly. It was speculated that residual tumor cells in the nerve tissue surrounding pancreas and superior mesenteric artery, residual tumor cells was presenced in neuroplexus and peripheral part of ganglia (positive margins) after lymph

node dissection expand ${ }^{[22]}$. The presence of perineural invasion have been found in more than $50 \%$ of cases, which showed that perineural invasion was earlier than lymph node metastases ${ }^{[23]}$.

\section{Conclusion}

these data demonstrated that the presence of multiple metastatic lymph nodes with tumor size was correlated with overall survival in univariate and multivariate analyses. We performed multivariate analysis with nine factors as shown in Table 1 because the number of samples in the present study was small. To further determine the prognostic factors for pancreatic cancer surgery, we should clarify the establishment and/or growth of lymph node metastases and tumor size associated with the growth trait and expand the sample number to study the factors influencing survival of pancreatic carcinoma resection in the future.

\section{Declarations}

\section{Ethics approval and consent to participate}

Institutional Review Board approval was obtained by all participating institutions (Hubei University of Medicine, Wuhan University). informed consent, written, was obtained from all participants

\section{Consent to publication}

Not applicable.

\section{Availability of data and materials}


Not applicable.

\section{Competing interests}

No potential conflicts of interest were disclosed by the other authors.

\section{Funding}

The authors would like to thank all the patients and health controls for their invaluable cooperation and participation. This work was supported by funding from Natural Science Foundation of Hubei Provincial Department of Education (grant no. Q20162112), and Natural Science Foundation of the Bureau of Science and Technology of Shiyan City (grant no. 16Y61)

\section{Authors' contributions}

Wei Hu, Jiao Zhou, and Wenbo Zhou conceptualized the research question. Lun Wu, Shaohua Sun, Zhen Zhang, Hong-Sheng Hu, and Feng Shen conducted the research. Lun Wu, Shaohua Sun, and Zhen Zhang analyzed data. Wei Hu, Jiao Zhou, and Wenbo Zhou wrote the paper. Wei Hu, Hong-Sheng Hu, and Feng Shen had primary responsibility for final content. All authors aided in data interpretation, reviewed draft manuscripts, and read and approved the final manuscript.

\section{Acknowledgments}

Not applicable.

\section{References}

1. Shen $H$, Zhan $M$, Wang $W$, Yang $D$, Wang J. Impact of diabetes mellitus on the survival of pancreatic cancer: a meta-analysis. Onco Targets Ther. 2016; 9: 1679-88.

2. Camara SN, Yin T, Yang M, Li X, Gong Q, Zhou J, Zhao G, Yang ZY, Aroun T, Kuete M, Ramdany S, Camara AK, Diallo AT, Feng Z, Ning X, Xiong JX, Tao J, Qin Q, Zhou W, Cui J, Huang M, Guo Y, Gou SM, Wang B, Liu T, Olivier OE, Conde T, Cisse M, Magassouba AS, Ballah S, Keita NL, Souare IS, Toure A, Traore S, Balde AK, Keita N, Camara ND, Emmanuel D, Wu HS, Wang CY. High risk factors of pancreatic carcinoma. J Huazhong Univ Sci Technolog Med Sci. 2016; 36: 295-304. 
3. Kabashi S, Dedushi K, Ramadani N, Mucaj S, Hoxhaj A, Jerliu N. Pancreatic Carcinoma: the Disease that Kills. World J Oncol. 2016 ; 7: 13-16.

4. Yuan C, Morales-Oyarvide V, Babic A, Clish CB, Kraft P, Bao Y, Qian ZR, Rubinson DA, Ng K, Giovannucci EL, Ogino S, Stampfer MJ, Gaziano JM, Sesso HD, Cochrane BB, Manson JE, Fuchs CS, Wolpin BM. Cigarette Smoking and Pancreatic Cancer Survival. J Clin Oncol. 2017; 35: 1822-1828.

5. Antwi SO, Oberg AL, Shivappa N, Bamlet WR, Chaffee KG, Steck SE, Hébert JR, Petersen GM.. Pancreatic cancer: associations of inflammatory potential of diet, cigarette smoking and longstanding diabetes. Carcinogenesis. 2016; 37: 481-490.

6. Campa D, Pastore M, Capurso G, Hackert T, Di Leo M, Izbicki JR, Khaw KT, Gioffreda D, Kupcinskas J, Pasquali C, Macinga P, Kaaks R, Stigliano S, Peeters PH, Key TJ, Talar-Wojnarowska R, Vodicka P, Valente R, Vashist YK, Salvia R, Papaconstantinou I, Shimizu Y, Valsuani C, Zambon CF, Gazouli M, Valantiene I, Niesen W, Mohelnikova-Duchonova B, Hara K, Soucek P, Malecka-Panas E, Bueno-DeMesquita HB, Johnson T, Brenner H, Tavano F, Fogar P, Ito H, Sperti C, Butterbach K, Latiano A, Andriulli A, Cavestro GM, Busch ORC, Dijk F, Greenhalf W, Matsuo K, Lombardo C, Strobel O, König AK, Cuk K, Strothmann H, Katzke V, Cantore M, Mambrini A, Oliverius M, Pezzilli R, Landi S, Canzian F. Do pancreatic cancer and chronic pancreati-ctis share the same genetic risk factors? A PANcreatic Disease ReseArch (PANDoRA) consortium investigation. Int J Cancer. 2018; 142(2): 290296.

7. Kirkegård J, Mortensen FV, Cronin-Fenton D. Chronic Pancreatitis and Pancreatic Cancer Risk: A Systematic Review and Meta-analysis. Am J Gastroenterol. 2017; 112: 1366-1372.

8. Smiley K, Malhotra R, Peche W, Langell JT. Unresectable Pancreatic Adenocarcinoma: Eight Years Later. World J Oncol. 2016; 7: 17-20.

9. Cardin DB, Goff LW, Chan E, Whisenant JG, Dan Ayers G, Takebe N, Arlinghaus LR, Yankeelov TE, Berlin $J$, Merchant N. Dual Src and EGFR inhibition in combination with gemcitabine in advanced pancreatic cancer: phase I results: A phase I clinical trial. Invest New Drugs. 2018; 36:442-450.

10. Ishitobi M, Fukui R, Hashimoto Y, Kittaka N, Nakayama T, Tamaki Y. pTis and pT1a Ipsilateral Breast Tumor Recurrence Is Associated with Good Prognosis after Salvage Surgery. Oncology. 2018; 94: 12-18.

11. Robert M, Jarlier M, Gourgou S, Desseigne F, Ychou M, Bouché O, Juzyna B, Conroy T, Bennouna J. Retrospective Analysis of CA19-9 Decrease in Patients with Metastatic Pancreatic Carcinoma Treated with FOLFIRINOX or Gemcitabine in a Randomized Phase III Study (ACCORD11/PROD IGE4). Oncology. 2017; (6). doi: 10.1159/000477850.

12. Meng Q, Shi S, Liang C, Liang D, Xu W, Ji S, Zhang B, Ni Q, Xu J, Yu X. Diagnostic and prognostic value of carcinoembryonic antigen in pancreatic cancer: a systematic review and meta-analysis. Onco Targets Ther. 2017; 10: 4591-4598. 
13. Kreppel M, Amir Manawi NN, Scheer M, Nickenig HJ, Rothamel D, Dreiseidler T, Drebber U, Zinser M, Zöller JE, Guntinas-Lichius O, Preuss SF. Prognostic quality of the Union Internationale Contrele Cancer/American Joint Committee on Cancer TNM classification, 7th edition, for cancer of the maxillary sinus. Head Neck. 2015; 37: 400-406.

14. U Ishimoto, S Kondo, A Ohba, M Sasaki, Y Sakamoto. Prognostic Factors for Survival in Patients with Advanced Intrahepatic Cholangiocarcinoma Treated with Gemcitabine plus Cisplatin as First-Line Treatment. Oncology. 2018; 94: 72-78.

15. Hiromichi Nakayama, Kenoki Ohuchida, Masaki Yoshida, Tetsuyuki Miyazaki, Shin Takesue, Toshiya Abe, Sho Endo, Kazuhiro Koikawa, Takashi Okumura, Taiki Moriyama, Kohei Nakata, Yoshihiro Miyasaka, Kengo Shirahane, Tatsuya Manabe, Takao Ohtsuka, Hiroki Toma, Yohei Tominaga, Eishi Nagai, Kazuhiro Mizumoto, Yoshinao Oda, and Masafumi Nakamura. Degree of desmoplasia in metastatic lymph node lesions is associated with lesion size and poorprognosis in pancreatic cancer patients. Oncol Lett. 2017; 14: 3141-3147.

16. Vyas SJ, Puri YS, John BJ, Yu D, Watkins J, Imber C, Fusai G, Arjun S, Sharma D, Davidson BR, Malago M, Rahman S. Radiological tumor density and lymph node size correlate with survival in resectableadenocarcinoma of the pancreatic head: A retrospective cohort study. J Cancer Res Ther. 2016; 12: 417-421.

17. Yang L, Yang Z, Li D, Liu Z, Zou Q, Yuan Y, Xu H. Overexpression of FZD1 and CAIX are Associated with Invasion, Metastasis, and Poor-Prognosis of the Pancreatic Ductal Adenocarcinoma. Pathol Oncol Res. 2018; 24: 899-906.

18. Wang F, Gill AJ, Neale M, Puttaswamy V, Gananadha S, Pavlakis N, Clarke S, Hugh TJ, Samra JS. Adverse tumor biology associated with mesenterico-portal vein resection influences survival in patients with pancreatic ductal adenocarcinoma. Ann Surg Oncol. 2014; 21: 1937-1947.

19. Battini S, Faitot F, Imperiale A, Cicek AE, Heimburger C, Averous G, Bachellier P, Namer IJ. Metabolomics approaches in pancreatic adenocarcinoma: tumor metabolism profiling predicts clinical outcome of patients. BMC Med. 2017; 15: 56.

20. Liu C, Tian X, Xie X, Gao H, Zhuang Y, Yang Y. Comparison of Uncinate Process Cancer and NonUncinate Process Pancreatic Head Cancer. J Cancer. 2016; 7: 1242-9.

21. Göhrig A, Detjen KM, Hilfenhaus G, Körner JL, Welzel M, Arsenic R, Schmuck R, Bahra M, Wu JY, Wiedenmann B, Fischer C. Axon guidance factor SLIT2 inhibits neural invasion and metastasis in pancreatic cancer. Cancer Res. 2014; 74: 1529-40.

22. Heinrich S, Lang H. Neoadjuvant Therapy of Pancreatic Cancer: Definitions and Benefits. Int J Mol Sci. 2017;18. pii: E1622. 
23. Rishi A, Goggins M, Wood LD, Hruban RH. Pathological and molecular evaluation of pancreatic neoplasms. Semin Oncol. 2015; 42: 28-39.

\section{Tables}

[Due to technical limitations, the tables could not be displayed here. Please see the supplementary files section to access the tables.]

Table 1 the results of univariate analysis of 36 cases of pancreatic cancer patients after the surgery

Table 2 The results of multivariate statistical analysis of COX regression model of 36 cases of pancreatic cancer patients after the surgery

\section{Figures}

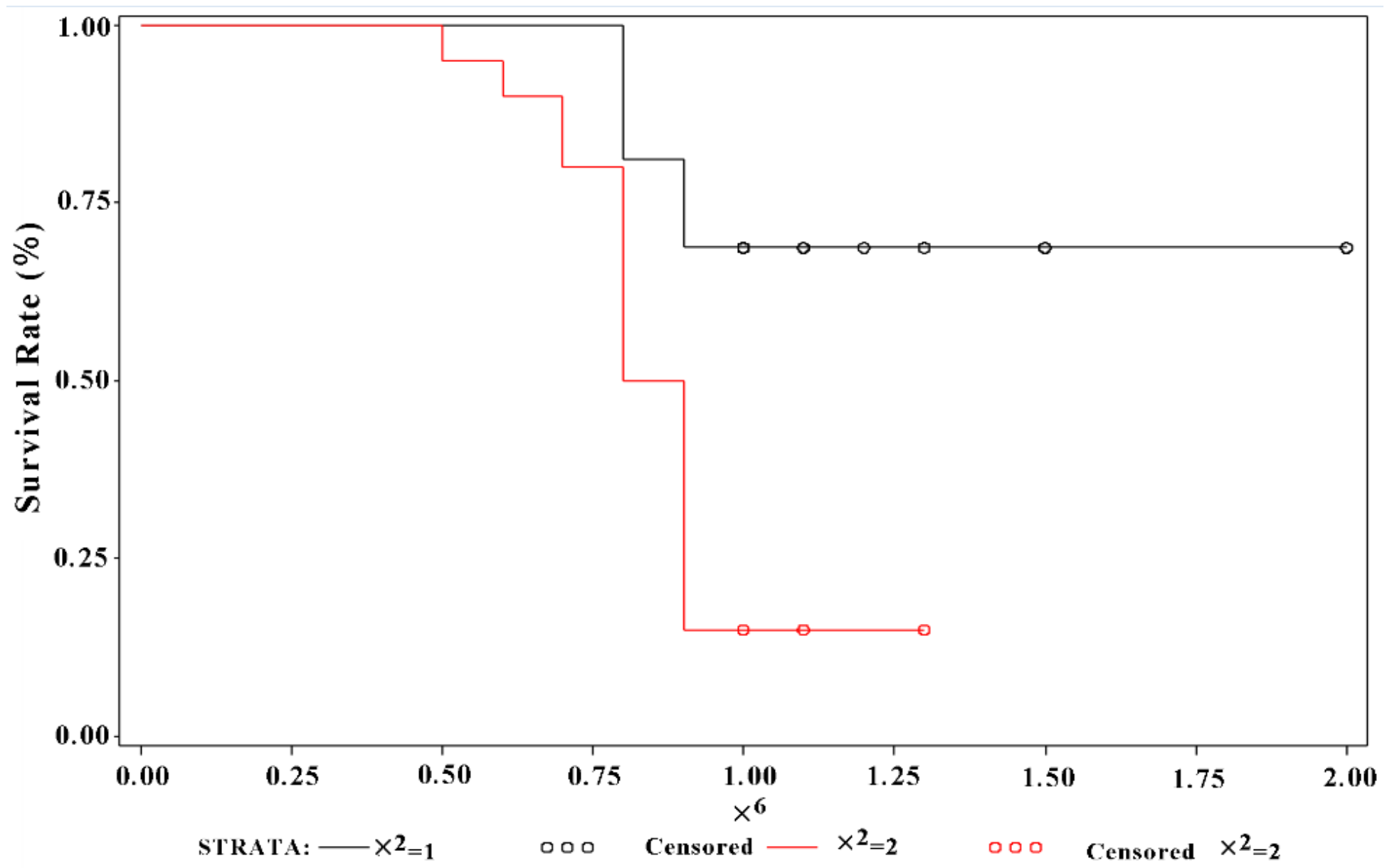

\section{Figure 1}

Survival curve of seventy-two patients with lymph node metastasis (red line) or no lymph node metastasis (black line). 


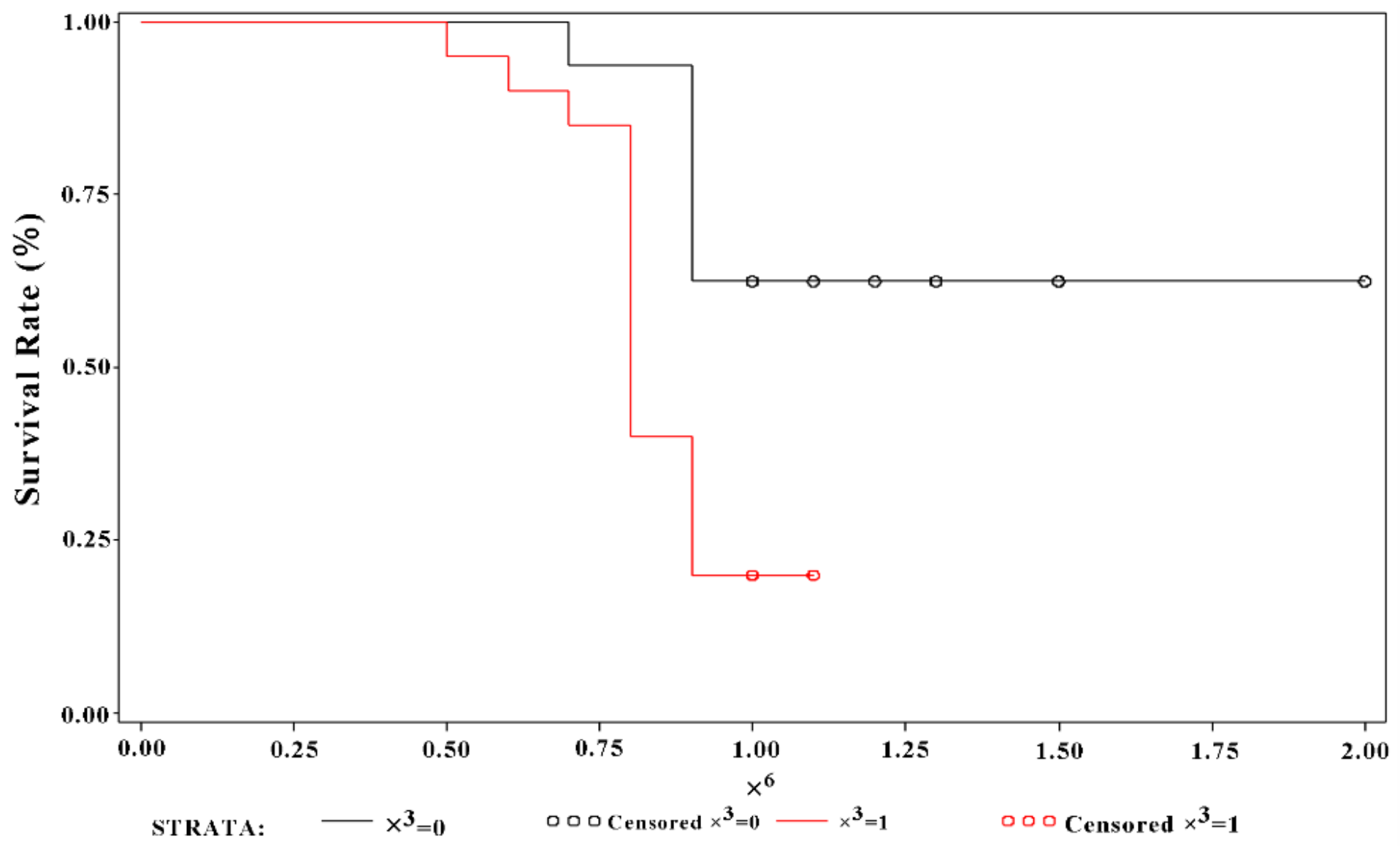

Figure 2

Survival curve of seventy-two patients with diameter of the tumor (red, $\varangle 4 \mathrm{~cm}$; black, $\leq 4 \mathrm{~cm}$ ).

\section{Supplementary Files}

This is a list of supplementary files associated with this preprint. Click to download.

- Tabl2.tif

- Tabl1.tif 